\title{
Is virtual existence our new reality?
}

\author{
David Sarraf $^{1} \cdot$ Danielle Rachel Sarraf $^{2} \cdot$ SriniVas Sadda $^{3}$
}

Received: 8 May 2020 / Revised: 8 May 2020 / Accepted: 12 May 2020 / Published online: 25 May 2020

(C) Springer-Verlag GmbH Germany, part of Springer Nature 2020

The COVID-19 crisis knows no boundaries, and this tragic pandemic has put everyone, rich and poor and obscure and famous, on red alert. Eye specialists for the most part have been away from the front lines; however, it is interesting that the first documented encounter of infected coronavirus patients was by a heroic ophthalmologist in Wuhan who tragically succumbed to this disease [1]. In addition, a number of brave ophthalmologists have volunteered to wage battle in ravaged emergency rooms (ER) and intensive care units (ICU) around the world. These courageous souls represent the best of our community during very difficult circumstances, and we are very proud of their contributions.

There are many other stories of heroism that have come to light especially among those on the front lines during these tough times, and deservedly, these efforts have garnered a great deal of attention and media headlines. But it is surprising that there has been a dearth of discussion and discourse in the media regarding the trending attitudes and cultures of our society that are ever more apparent during a pandemic crisis. A culture that more and more is moving in the direction of a virtual existence with a preference to limit human contact and only communicate through a digital interface that eliminates our deepest anxieties and fears.

It is clear that we have encountered a new enemy. Fascist dictators with reckless tendencies or religious fanaticisms or genocidal obsessions have been replaced by a biologic killer. Our soldiers no longer wear military uniforms but instead they don surgical scrubs and white coats. Our politicians no longer send young healthy men to an uncertain destiny in killing

This article is part of the topical collection Perspectives on COVID-19.

David Sarraf

dsarraf@ucla.edu

1 Stein Eye Institute, UCLA, 100 Stein Plaza, Los Angeles, CA 90095, USA

2 Washington University in St. Louis, St. Louis, MO, USA

3 Doheny Eye Institute, UCLA, Los Angeles, CA, USA fields. Thankfully, our leaders now prioritize the life of our citizens even the weak and infirmed who may already be at death's door. For this, we should be grateful that we live in a world where we are all dedicated to peace and the sanctity of life.

The parallels with war time tragedies are inescapable. In fact, recently a local health official [2] quoted the great Winston Churchill, who charismatically guided the UK and the allied nations through the Second World War to eventual victory. In an effort to urge greater resiliency of her constituency in the fight against the coronavirus which continues to infect thousands of people every day, just here in the state of California, she noted: "...this is not the end. It is not even the beginning of the end. But it is, perhaps, the end of the beginning."

But we are drawn to another famous quote by a contemporary of Churchill, Franklin D. Roosevelt: "We have nothing to fear but fear itself." The political policies to fight COVID-19 and "flatten the curve" of infection have been successful and have reduced conversion rates so that hospital ERs and ICUs are not overburdened, ensuring that patients with coronavirus throughout the world receive optimal care. It is clear that one of the reasons for the higher death rate in Italy may relate to severely ill COVID patients who did not receive necessary supportive care in time because hospitals were overwhelmed by deathly sick coronavirus patients. Here in California, social isolation policies have thus far been very successful, and the curve has been presumably flattened. Hospitals and ICUs across the state are operating under capacity, and all patients have been receiving the supportive care that they need [3].

Yet, is there an end in sight? New coronavirus infections are continuing at an unrelenting pace. Here in California, the daily rate of new infections has steadily risen at approximately 1500 to 3000 cases per day, and mortality has continued at approximately 60 to 80 deaths or more per day for the last several weeks, despite increasingly warm temperatures [3]. Does it make sense therefore to continue to isolate communities when our hospitals are operating comfortably and infection rates are not abating? What is the cost of this policy? This is an ethically, complicated question, as there is no ideal or 
perfect solution. Morbidity and mortality from COVID-19 are a terrible tragedy but they are relatively easy to track. The long-term consequences of current policy in terms of mental health and societal decay are much more difficult to quantify.

Nevertheless, it is clear that the toll of social isolation has been heavy. So far, almost 30 million jobs have been lost, the unemployment rate has ballooned to $23 \%$, and 22 million citizens in the USA alone have filed for unemployment insurance from the government which will have to doll out hundreds of millions, if not billions, of dollars as compensation [4, 5]. As President Trump has stated, we now have the worst unemployment rate since the Great Depression $[4,5]$. Hundreds and thousands of businesses, especially small businesses, are at risk of collapse as they dip into their limited reserves to pay employees shuttered at home and attempt to cover overhead without any stream of cash flow for the last several months. The growing societal problem of the homeless, already a major issue in urban cities like San Francisco and Los Angeles, is accelerating, and this may establish a nidus for an even greater risk of infection from COVID and other insipid diseases. Mental health has suffered as masses of people sit idle at home unable to work and provide for their families and frustrated at the loss of their civil liberties and privileges such as playing in the park or walking on the beach. In fact, $45 \%$ of US adults concede that their mental health has deteriorated due to the COVID-19 pandemic and the shelterin-place orders, and calls and texts to crisis lines have dramatically increased [6]. Depression, suicide, and domestic violence are becoming pervasive problems in many of our struggling communities during this crisis [7].

Is it time to stop running and hiding? As FDR stated so long ago, is fear our greatest enemy? Are we climbing a slippery slope of a virtual existence where we will no longer condone human contact and interaction? Will we forever communicate on line through webcasts and zoom sessions forsaking all face to face exchange? It is clear that COVID is not going away anytime soon. The risk of infection may continue throughout the coming months and even into next year. Until the advent of herd immunity or a vaccine, which both seem many months away, we cannot evade this invisible enemy. Perhaps, the focus of our policies should be more targeted and aimed toward protecting and isolating the elderly and the infirmed and those with comorbid conditions until a vaccine or effective antiviral treatment is available. Continued implementation of social distancing policies and reduction of transmission through improved community hygiene is essential while gradually restarting the economy and reintroducing civil liberties so that one crisis will not be replaced by another.

It is clear that we are a social people by nature. But this way of life is being eroded away by the digital revolution and by our fears of human contact. Already millennials and centennials seem to communicate more and more on a digital interface and eschew face to face exchange. The current crisis and our raised fears and anxieties of infection threaten to drive an even greater wedge through human connection. Communication through a screen or digital interface to allay our ever-growing unease with human contact sadly may become our predominate means of interaction. Certainly, this is not the direction we want to go. We stand to lose so much through these forms of aseptic communication that lack vibrancy and engagement and are void of dynamic interchange and instruction. Virtual reality will lead to a world devoid of soul and emotion and human spirit, a sterile and lifeless way of life in which the many benefits of face to face engagement will be completely lost. We need to overcome our fears and reach out and touch the awesome world that we live in and understand that we cannot hide at home behind our computers forever in a virtual reality devoid of human intimacy and vibrant exchange.

\section{References}

1. Petersen E, Hui D, Hamer DH et al (2020) Li Wenliang, a face to the frontline healthcare worker. The first doctor to notify the emergence of the SARS-CoV-2, (COVID-19), outbreak. Int J Infect Dis 93: 205-207.2020

2. Fry H, Luna T, Lin R-G II, Dolan M. L.A (2020) County reports 42 more coronavirus deaths, a new single-day high. L.A. Times. 15 April 2020. https://www.latimes.com/california/story/2020-04-15/ this-is-not-the-end-officials-say-its-too-early-to-scale-backcoronavirus-restrictions. Accessed on 6 May 2020

3. COVID-19 (2020) California Department of Public Health. 5 May 2020. cdph.ca.gov/covid19. Accessed on 6 May 2020

4. Cox J (2020) An unemployment rate of 23\%? The real jobless picture is coming together." CNBC. 23 April 2000. https://www.cnbc. com/2020/04/23/an-unemployment-rate-of-23percent-the-realjobless-picture-is-coming-together.html. Accessed on 6 May 2020

5. Lambert L (2020) "Real unemployment rate soars past 20\%-and the U.S. has now lost 26.5 million jobs." Fortune. 23 April 2000. https:// fortune.com/2020/04/23/us-unemployment-rate-numbers-claimsthis-week-total-job-losses-april-23-2020-benefits-claims/. Accessed on 6 May 2020

6. Chidambaram P (2020) "The implications of COVID-19 for mental health and substance abuse." Kaiser Family Foundation 21 April 2020. https://www.kff.org/health-reform/issue-brief/theimplications-of-covid-19-for-mental-health-and-substance-use/. Accessed on 6 May 2020

7. Taub A (2020) "A new covid-19 crisis: domestic abuse rises worldwide." The New York Times.” April 6 2020. https://www.nytimes. com/2020/04/06/world/coronavirus-domestic-violence.html. Accessed on 6 May 2020

Publisher's note Springer Nature remains neutral with regard to jurisdictional claims in published maps and institutional affiliations. 